\title{
Use of bolted shear connectors in composite construction
}

\author{
X. Dai*, D. Lam, T. Sheehan, J. Yang and K. Zhou \\ School of Engineering, University of Bradford, United Kingdom \\ *corresponding author, e-mail address: x.dai@bradford.ac.uk
}

\begin{abstract}
Composite beam incorporated steel profiled decking has been extensively used for multistorey buildings and is now one of the most efficient and economic form of flooring systems. However, the current composite flooring system is not demountable and would require extensive cutting on site during demolition, and the opportunity to reuse the steel components is lost even though these components could be salvaged and recycled. This paper presents the use of high strength bolts as shear connectors in composite construction, the shear behaviour and failure modes were observed and analysed through a series of pushoff tests and numerical simulation. The results highlighted the structural behaviour of three different demountable shear connection forms in which continuous slabs or un-continuous slabs were used. Numerical models were validated against experimental observation. Both experimental and numerical results support the high strength bolts used as demountable shear connectors and lead to a better understanding to the behaviour of this form of shear connectors.
\end{abstract}

Keywords: Bolted shear connector; composite construction; experimental study; numerical modelling.

\section{Introduction}

In recent years, building environment related issues such as sustainability, energy saving, deconstructed building system, construction member and material reuse and recycling etc. have been significantly emphasized to improve the current building environment and enable the future generations to have a better life and enough resources to fulfil their needs. It has been recognized that construction has a great impact on the living environment, especially the demolition and handling of building structures after their design life.

Steel-concrete composite structures have been used in the construction industry since the early 1920s. As a cost-effective construction system for multi-storey buildings and bridges owing to the composite action between steel beams and concrete slabs, currently this structural type is extensively employed in construction practice for high-rise buildings. However currently most composite systems use welded shear connectors to achieve the composite action between the steel beam and the composite concrete slab. These welded shear connections make dismantling, adaptation (alteration) and deconstruction of the composite structure almost impossible when composite structures reach the end of their design life. These welded shear connectors also have disadvantages with respect to the reuse, replacement and repair of structural members, such as a steel beam or a damaged concrete slab. Therefore, recently, researchers have been searching for innovative connection systems to overcome the weakness of the welded shear connector.

To make the deconstruction of composite systems possible, bolts used as demountable shear connectors might be a solution, however so far bolts have not been extensively adopted in construction practice to fulfil the deconstruction aim. Although research on the use of bolted shear connectors started in 1960s, 1970s and 1980s by Dallam [1], Marshall et al. [2], Dedic, Klaiber [3] and Hawkins [4], more research is needed on the behaviour of demountable shear connectors in composite structures to consider structure deconstruction, member replacement and repair. In the above-mentioned research 
work, high strength friction grip bolts in solid concrete slabs were investigated by using the push out technique and full-scale composite beam tests. These bolts were often placed inside the concrete slab through the post installation method after casting the concrete slab. However, the post installation method is time-consuming. In recent years, bolts used as shear connectors were studied. Atei et al [5] investigated the behaviour of high strength friction grip bolts in geo-polymer concrete slab and normal concrete slabs respectively through push tests and fullscale composite beam tests. Lee and Bradford [6] conducted push-out tests according to EC4, using M20 Gr8.8 bolted shear connectors with a single embedded nut while Ataei and Bradford [7] tested pretension bolts with precast solid concrete slabs for a demountable connection system. Pavlovic et al. [8] studied the M16 Gr8.8 bolted shear connector through push-off tests in solid slabs and compared the experimental results with welded headed shear studs in solid slabs. It was found that the Gr8.8 bolted shear connectors with a single embedded nut achieved about $95 \%$ of the shear resistance under static loads, but the stiffness was reduced by $50 \%$ compared to the welded headed stud. A fullscale composite beam test with profiled metal decking was reported by Moyniah and Allowed [9] using M20 Gr 8.8 bolts as shear connectors in a composite beam. The research showed that these bolts may be used as demountable connectors and they behaved in a similar way to welded connectors and the slabs can be taken off easily from the steel beam. Lam and Saveri [10] and Dai et al [11] investigated the load slip behaviour of modified demountable shear connectors through push off tests and finite element modelling. Naveed et al [12-13] experimentally studied the modified demountable shear connectors in composite slabs by push off tests and full-scale composite beam systems. It was found that the demountable shear connectors completely fulfilled the aim of deconstruction of the composite system.

This paper presents a primary research work on use of high strength bolts as shear connectors in composite construction. The shear behaviour and failure modes are analysed through a series of push-off tests and numerical simulations. The results compare the performance of composite systems using continuous slabs and discontinuous slabs with edge trims and U-bars. Numerical models are validated against experimental observations. The experimental and numerical results confirm that it is beneficial to use the high strength bolts as demountable shear connectors. The results lead to a better understanding to the behaviour of this form of shear connectors.

\section{Experimental Study}

\subsection{Test specimens and material properties}

To assess the shear resistance, stiffness and ductility of demountable bolted shear connectors, three different push off specimen types, each type including three identical specimens and in total 9 specimens, were tested in the University of Bradford. As shown in Fig 1, the type P2.1 specimens consist of continuous concrete slabs, continuous A193 mesh and a continuous B500BØ10mm reinforcement cage at the slab toe, M20 G8.8 bolts/nuts, continuous CF80 metal decking profile and a UC $254 \times$ $254 \times 73$ beam. The type P2.2 specimens consist of partially discontinuous concrete slabs with a gap of $2 \mathrm{~mm}, 130 \mathrm{~mm}$ depth metal edge trim profiles, continuous A193 mesh but separate B500BØ $10 \mathrm{~mm}$ reinforcement cages at the slab toe, M20 G8.8 bolts/nuts, U-bars at each bolt, separate CF80 metal decking profiles and UC $254 \times 254 \times 73$ beam. The type P2.3 specimens consist of separate concrete slabs with a gap of 2 $\mathrm{mm}, 150 \mathrm{~mm}$ depth metal edge trim profiles, separate A193 mesh and separate B500B Ø10mm reinforcement cages at the slab toe, M20 G8.8 bolts/nuts, U-bar at each bolt, separate CF80 metal decking profiles and UC $254 \times 254 \times 73$ beam.

The dimension of the continuous slab are $900 \times 610 \mathrm{~mm}$ with a maximum slab depth of $150 \mathrm{~mm}$. For the discontinuous slab, two separate slabs cover the continuous slab dimension and the gap between the separate slabs is $2 \mathrm{~mm}$. The length of M20 G8.8 bolts used is $185 \mathrm{~mm}$ and the $175 \mathrm{~mm}$ shank is fully threaded. The nominal height of the bolted connectors that were embedded into concrete for all the specimens was $120 \mathrm{~mm}$ and two nuts were used for each bolt connector and one nut was embedded in concrete. Two bolts were used per trough and the spacing was $100 \mathrm{~mm}$ and the spacing of connectors in the two troughs was $300 \mathrm{~mm}$ to match the trough space of the CF80 deck profile. The minimum distance between the shear connectors and the reinforcement mesh/U-bars was $50 \mathrm{~mm}$. 
The composite slabs for each specimen were casted horizontally with the same concrete and cured in an open-air environment. The strength of the slab concrete was determined by taking the average strength of the cube specimens cured in the same condition as the tested specimens and tested on the test day. The profiled metal decking had a thickness of $0.9 \mathrm{~mm}$ and steel grade of S350. The profiled metal edge trim had a thickness of $1.0 \mathrm{~mm}$ and a steel grade of $\mathrm{S} 350$.

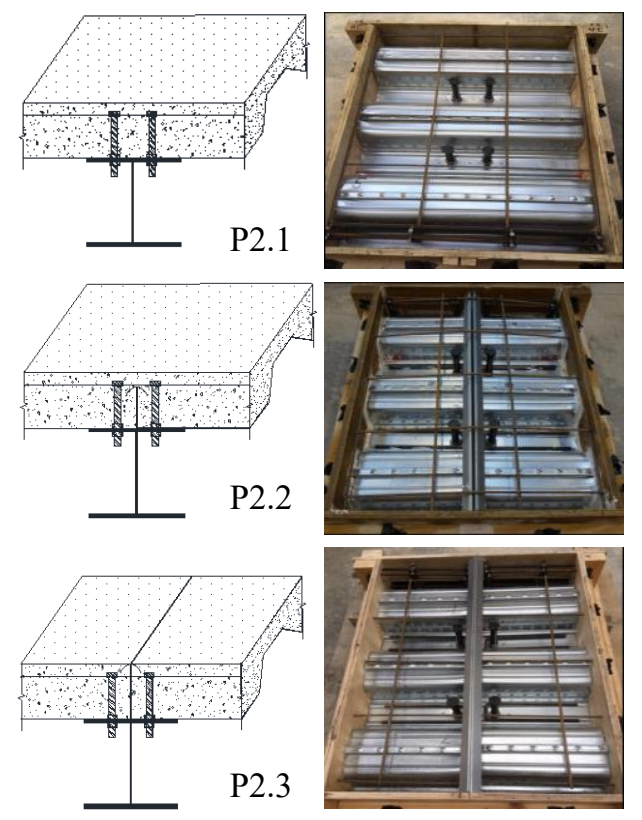

Fig. 1. Specimen components and formwork

\subsection{Test set up and instrumentation}

Fig. 2 shows a typical specimen set-up of the push-off tests. Eight linear variable displacement transducers (LVDTs) were installed vertically at the loading plate of the steel beam and the concrete slabs to measure the displacements, which subsequently were used to calculate the relative slip between the steel beam and the concrete slab. Strain gauges were installed in the vicinity of the bolt holes to monitor the difference between loads applied to the bolted shear connectors. The load versus displacement behaviour was recorded by the data logging system. In each type of specimen, the three identical specimens were tested based on the following three loading regimes. The $1^{\text {st }}$ specimen, continuous loading: single cycle of loading using load control at $20 \mathrm{kN} / \mathrm{min}$ up to the elastic limit and then using displacement control with $0.5 \mathrm{~mm} / \mathrm{min}$ pushing off until the specimen failure. The maximum load recorded in this specimen was used as a reference failure load for the second and third specimen tests. The $2^{\text {nd }}$ specimen, EC4 + Relaxation, the Eurocode 4 test regime was as follows: firstly 25 loading cycles were applied between $5 \%$ and $40 \%$ of the maximum load obtained from the first tested specimen, then the load was increased towards the maximum load using the same loading regime as that of the first specimen. Once the maximum load was reached, this was followed by a 5 minute waiting period before further increasing the displacement. When the load dropped down to $95 \%$ of the maximum load, this was followed by a second 5 minute waiting period before using displacement control with a push-off rate of $0.5 \mathrm{~mm} / \mathrm{min}$ until the specimen failure occurred. For the $3^{\text {rd }}$ specimen, stepwise unloading was employed: first, cyclic loading was applied via the EC4 test regime ( 25 cycles between $5 \%$ and $40 \%$ of the maximum load of the first specimen), then un-loading to the $5 \%$ of the maximum load, then loading towards the maximum load with $0.5 / 1 \mathrm{~mm}$ increments, after reaching the maximum load, the test continued under displacement control at a rate of $0.5 \mathrm{~mm} / \mathrm{min}$ until reaching specimen failure. A $1000 \mathrm{kN}$ actuator was employed for loading.

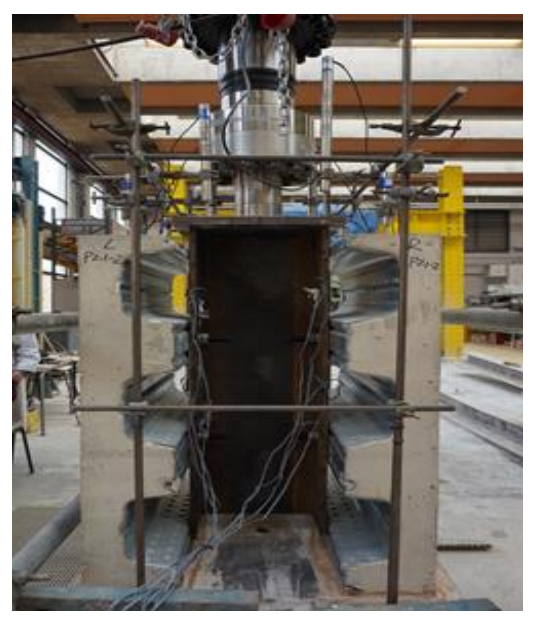

Fig. 2. Test set-up and instrumentation

\subsection{Experimental results}

Table 1 summarizes the shear connector resistance, slip behaviour and failure modes for 9 specimens in 3 different types. It can be seen that the type P2.2 specimens have the highest resistance, followed by the type P2.3 specimens. The resistance of type $\mathrm{P} 2.1$ specimens is much lower. The possible reason for P2.2 and P2.3 specimens having higher resistance is due to the use of edge trims and U-bars at each bolt. Although the concrete slabs were discontinuous, 
Table 1. Summary of shear connector resistance, slip and failure modes

\begin{tabular}{cccccc}
\hline $\begin{array}{c}\text { Specimen } \\
\text { ID }\end{array}$ & $\begin{array}{c}\text { Concrete cube } \\
\text { strength (MPa) }\end{array}$ & $\begin{array}{c}\text { Load at 6mm } \\
\text { slip (kN/bolt) }\end{array}$ & $\begin{array}{c}\text { Max load } \\
\text { (kN/bolt) }\end{array}$ & $\begin{array}{c}\text { Slip value at max } \\
\text { load (mm) }\end{array}$ & $\begin{array}{c}\text { Mode of } \\
\text { failure }\end{array}$ \\
\hline $\mathrm{P} 2.1-1^{\text {st }}$ & 47.59 & 34.42 & 36.51 & 7.26 & Concrete \\
$\mathrm{P} 2.1-2^{\text {nd }}$ & 47.59 & 38.31 & 41.17 & 6.22 & Concrete \\
$\mathrm{P} 2.1-3^{\text {rd }}$ & 50.95 & 33.05 & 36.74 & 2.91 & Concrete \\
\hline $\mathrm{P} 2.2-1^{\text {st }}$ & 47.25 & 70.85 & 73.58 & 7.07 & Concrete \\
$\mathrm{P} 2.2-2^{\text {nd }}$ & 47.25 & 70.95 & 80.42 & 8.35 & Concrete \\
$\mathrm{P} 2.2-3^{\text {rd }}$ & 47.25 & 75.81 & 78.90 & 7.54 & Concrete \\
\hline $\mathrm{P} 2.3-1^{\text {st }}$ & 47.59 & 61.84 & 68.07 & 8.51 & Concrete \\
$\mathrm{P} 2.3-2^{\text {nd }}$ & 47.59 & 62.38 & 69.79 & 9.03 & Concrete \\
$\mathrm{P} 2.3-3^{\text {rd }}$ & 50.95 & 65.60 & 72.08 & 8.68 & Concrete \\
\hline
\end{tabular}
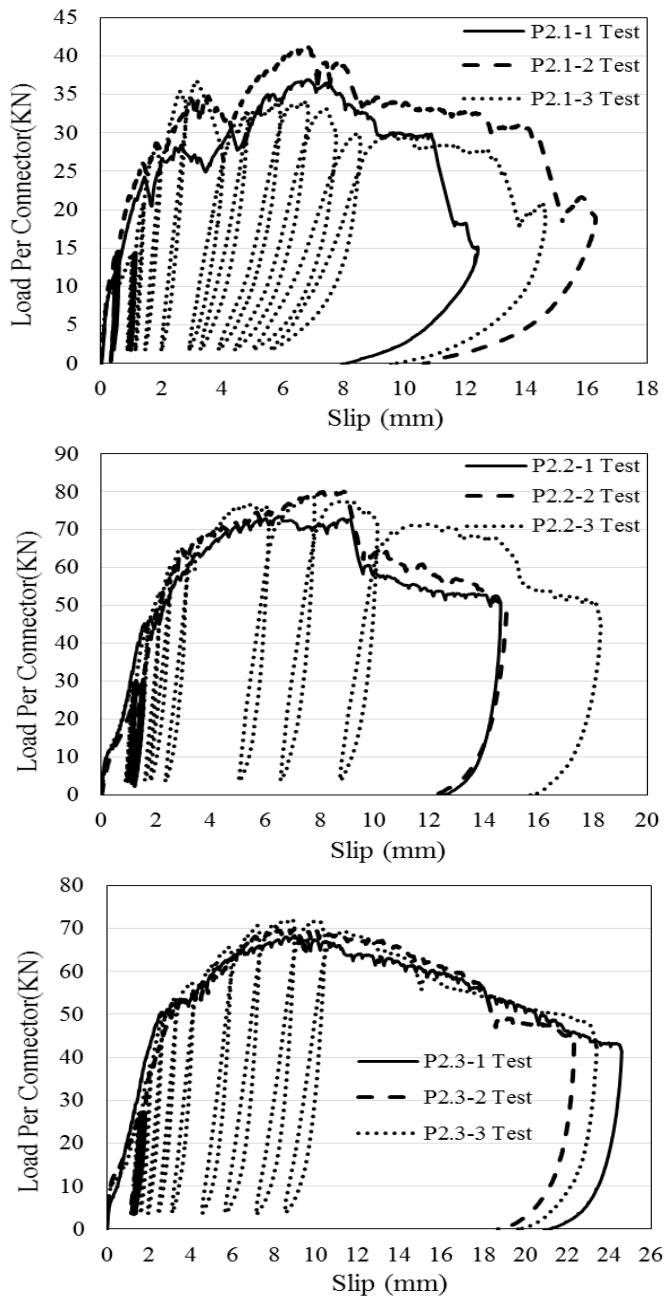

Fig. 3. Load versus slip relationships

the edge trims provided a strong confinement to the concrete around the shear connectors, as well the U-bars that reinforced the concrete in the vicinity of the bolts. In addition, the edge trims directly bore part of the bending applied to the slab transferred from the bolts and thus increased the shear connector resistance. The load versus slip behaviour of all 9 specimens is presented in Fig. 3. These load-slip curves show a clear elastic and plastic portion. Although the P2.2 and P2.3 specimens have a lower initial stiffness and a higher initial slip due to the $2 \mathrm{~mm}$ gap between the separate slabs, the ductility is much better than the P2.1 specimens. From Table 1, the concrete strength of specimens P2.1-3rd and $\mathrm{P} 2.3-3 \mathrm{rd}$ is a little bit higher than that of other specimens, however this appears to have no evident effect on the resistance and ductility of the shear connections. All the specimens met the $6 \mathrm{~mm}$ slip limit required by EC4.
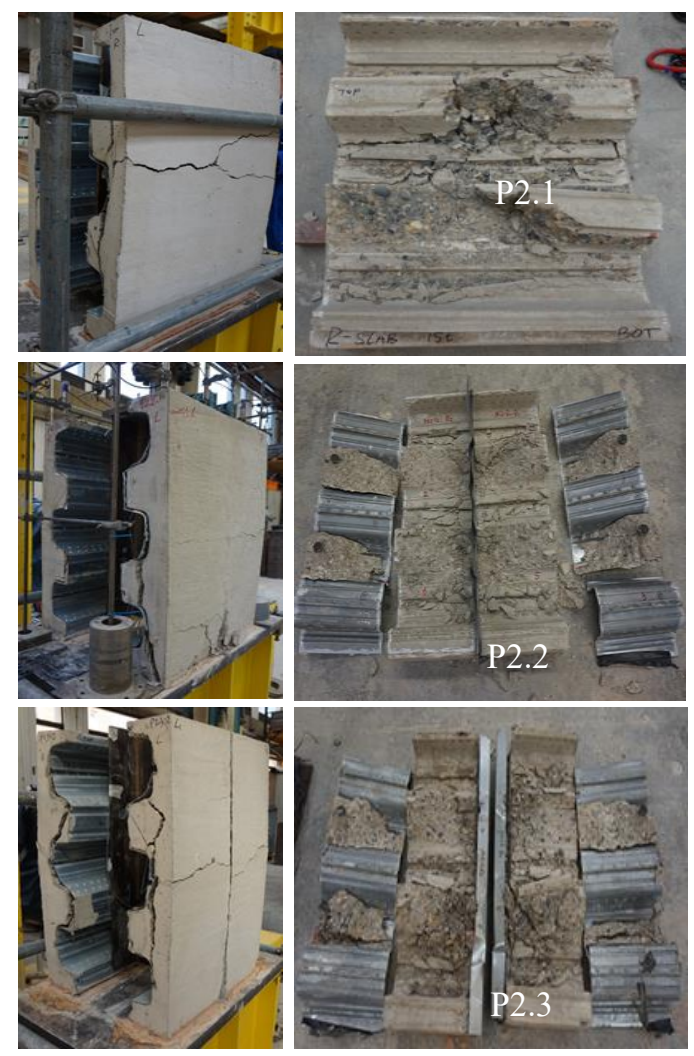

Fig. 4. Failure modes 
The test observations clearly showed that the main failure mode in all of these specimens was concrete failure with concrete crushing at the vicinity of the bolts and cracks occurred at the slab surface and rib roots. No connector fracture was observed, although some bolts showed slight bending after testing. As shown in Fig 4, evident cracks formed at the surface of the slab due to the tension induced by the slab bending. The concrete crushed at/from the vicinity of the connector and formed a cone shape around the shear connectors and the slab rib was fractured from the root due to shear force. It is noted the use of U-bars changed the failure mode from concrete crushing to a shear fracture of the ribs due to their reinforcement to the concrete.

\subsection{Summary}

After testing, the bolts/nuts could be undone easily and the slabs were easily separated from the steel beam. The P2.2 and P2.3 specimens using discontinuous slabs with edge trims and Ubars clearly had a higher shear capacity and better ductility than P2.1 specimens using continuous slabs. This indicates that the use of discontinuous slabs with edge trims and U-bars not only increases the shear connection resistance, but also provides ease for the deconstruction due to using "small" members. This will make the replacement and repair practical. The experimental observations support the use of composite beam system using discontinuous slabs with edge trims and U-bars.

\section{Numerical Model Development and Validation}

\subsection{Descriptions of FE model}

The nonlinear finite element software ABAQUS was used to develop the FE model for the push off test specimens. Considering the symmetrical condition of the tested specimens across the central line of the beam web, only half of the geometry of the specimen was used in the modelling calculation to achieve computational efficiency. This paper only shows the modelling and validation of the specimen with continuous slabs (P2.1) and specimen with fully discontinuous slabs (P2.3). Based on the components of the tested specimens, the FE model includes concrete slab, profiled metal decking, reinforcement steel cage, M20 G8.8 bolts/nuts, U-bars, profiled edge trim and steel beam. All components were created separately and then assembled together as models shown in the Fig. 5.
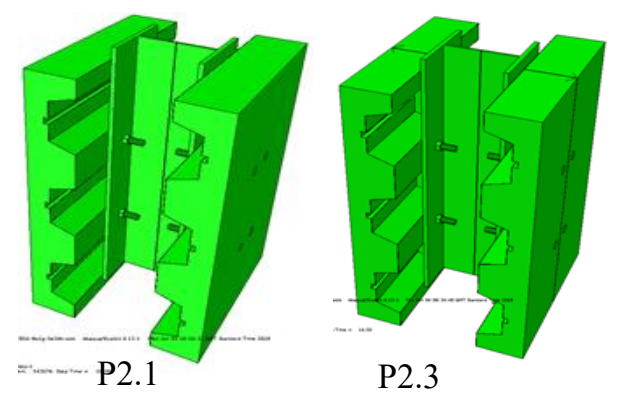

Fig. 5. Developed FE models using ABAQUS

Element type and mesh: The three dimensional eight-node solid brick elements C3D8R with reduced integration were adopted to mesh the concrete slab, steel beam, bolt and nut. The two-node truss elements T3D2 were used for the reinforcement steel cage and U-bars. Since both the profiled metal decking and the profiled metal edge trim are thin, shell elements with reduced integration (S4R) were used.

Interaction contact and constraint: In the modelling, contact pairs with appropriate behaviour were defined between interacting surfaces of different components. For interactions between concrete slabs and profiled metal decking, the "hard" contact condition was used for normal contact behaviour and the "penalty" contact condition with a coefficient of friction of 0.3 was adopted for tangential behaviour. For contact between metal decking and the steel beam and between bolts/nuts and the steel beam, "hard" contact was used for normal contact and "penalty" with a friction coefficient of 0.2 were used for tangential behaviour. The relationship/contact between bolts and concrete slabs is different. In view of the fact that the bolt threads were teethed together with the concrete, the tangential behaviour "rough" was used to restrain the slip. The normal interaction was still defined as "hard" contact. This behaviour was compared with tying (tie) the bolt shaft to the concrete, and similar results were obtained. Since the edge trim was partially inserted into the concrete, the slip between the slab and edge trim profile was limited. Therefore, in the model, the edge trim outside the concrete slab was "tied" to the concrete, while the edge trim inside the concrete slab was "embedded" in the concrete. Both reinforcement mesh/cage and U-bar were "embedded" into the concrete slab to assume a 
perfect bond. As with the tested specimens, a bolt hole of diameter $21 \mathrm{~mm}$ on the steel beam flange was adopted to accommodate the M20 bolt whose diameter was assumed to be $20 \mathrm{~mm}$. For specimen (P2.3) with discontinuous slabs, the gap between the edge trim surfaces was assumed to be $1 \mathrm{~mm}$. This might be smaller than the real gap in the tested specimens.

Material Properties: For the steel beam, of steel grade $\mathrm{S} 355$, the assumed yield strength was $350 \mathrm{~N} / \mathrm{mm}^{2}$, ultimate strength $480 \mathrm{~N} / \mathrm{mm}^{2}$, Young's modulus 210GPa and Poisson's ratio 0.3 . The bolt size and grade were M20 and G8.8, the assumed yield strength was $640 \mathrm{~N} / \mathrm{mm}^{2}$, the ultimate strength was $850 \mathrm{~N} / \mathrm{mm}^{2}$, Young's modulus was $210 \mathrm{GPa}$ and Poisson's ratio was 0.3 . For the A193 steel mesh, the reinforcement cage bar and U-bar were B500B/Ø10mm, both yield strength and ultimate strength were assumed to be $500 \mathrm{~N} / \mathrm{mm}^{2}$, Young's modulus was $210 \mathrm{GPa}$ and Poisson's ratio was 0.3 . From steel decking and edge trim profiles, the steel grade was S350 and the assumed yield strength was $350 \mathrm{~N} / \mathrm{mm}^{2}$, the ultimate strength was $450 \mathrm{~N} / \mathrm{mm}^{2}$, Young's modulus was $210 \mathrm{GPa}$ and Poisson's ratio was 0.3 .

For the slab concrete in most specimens, as shown in Table 1, the measured cubic compressive strength was in the range from 47.3 to $47.6 \mathrm{MPa}$, and the split tensile strength measured was from 2.5 to $2.7 \mathrm{~N} / \mathrm{mm}^{2}$. Therefore, in the FE modelling grade $\mathrm{C} 40 / 50$ concrete was adopted and the maximum tensile strength was assumed to be $2.6 \mathrm{~N} / \mathrm{mm}^{2}$.

\subsection{Model validation and comparison}

Fig. 6 compares the predicted slip-shear connector resistance relationship against the experimental results recorded from P2.1 and P2.3 specimens. Obviously, the comparison of the FE prediction and experimental results shows good agreement, although the FE prediction gave a higher initial stiffness and a higher ductility than those from the experimental results. The lower initial stiffness observed from tests might be resulting from the real specimen imperfection and setup tolerance whereas the FE model employed the ideal boundary condition and perfect set up. Clearly if $1 \mathrm{~mm}$ initial slip was applied (more reasonable if the $1 \mathrm{~mm}$ initial slip were introduced gradually from the beginning of loading to the first peak load) to the modelling results as shown in the Fig 5, it appears the prediction matches the experimental results more closely.
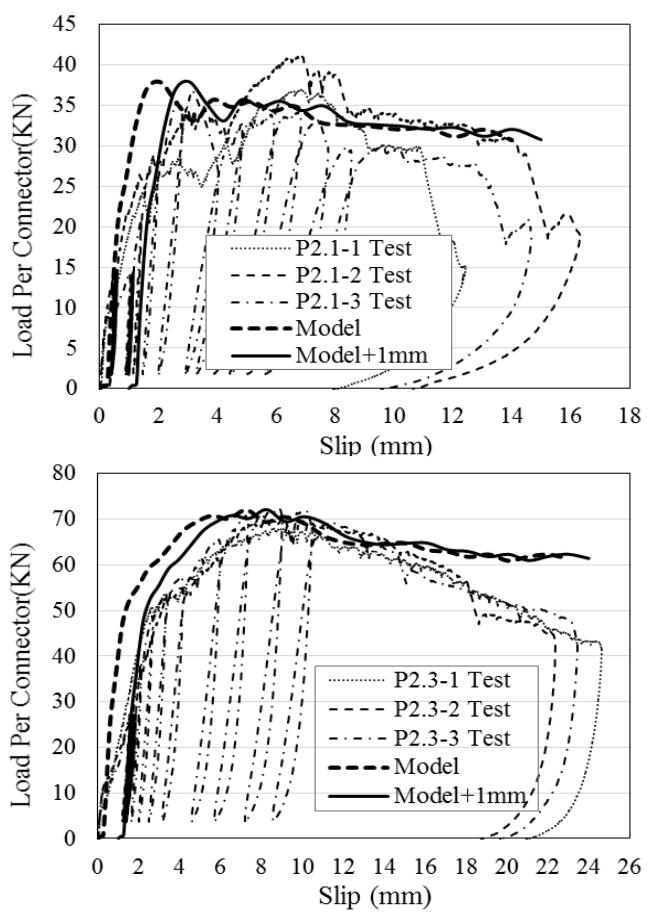

Fig. 6. Comparisons of load versus slip relationships
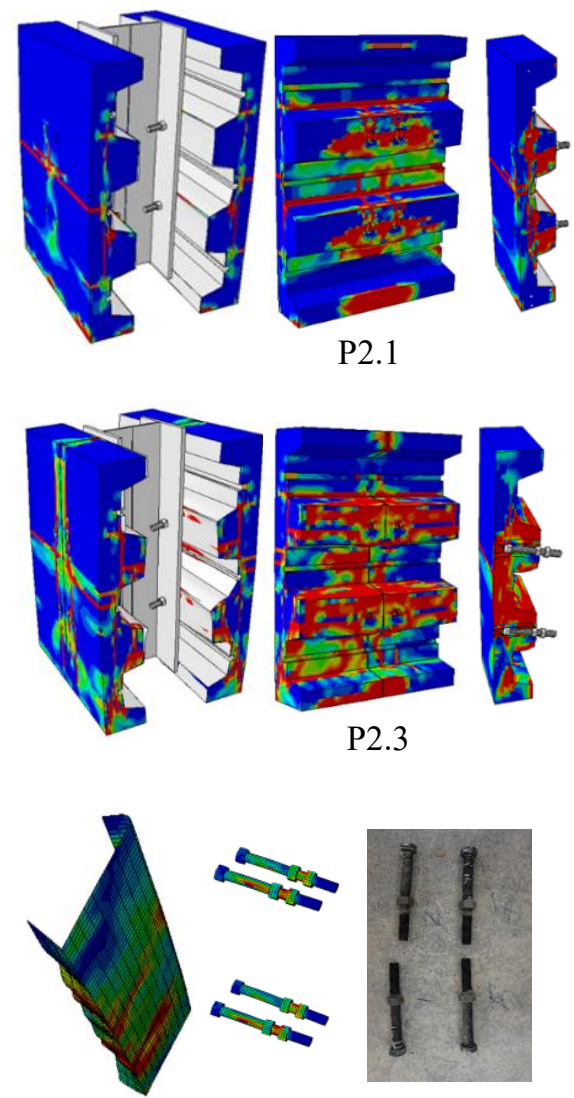

Fig. 7. Predicted failure modes by FE models 
Fig. 7 shows the concrete slab crack positions and concrete damage distribution. Compared with experimental observations shown in Fig. 4, it is clear that the FE prediction successfully captured the concrete cracks that occurred at the top surface of the slab due to the bending of the slab. Also, the prediction captured the cracks at the root of the rib resulting from the shear force transferred from the shear connectors. The positions and concrete damage patterns are similar to those observed from the tested specimens. As observed from tests, the FE prediction shows a slight deformation in the bolts and evident deformation in the edge trims. The validation indicates that the FE model could replicate the main failure modes and damage developments observed from the experimental study.

\section{Conclusions}

Nine push-off tests have been conducted to investigate the shear resistance, ductility and stiffness of the demountable shear connections using high strength bolts. An FE model was developed using software ABAQUS and validated against experimental results. The following conclusions can be drawn within the limitations of the research work:

(1) The high strength bolts, such as M20 G8.8, can be used as demountable shear connectors in a steel concrete composite beam system. Higher shear resistance and better ductility was observed from connection systems using discontinuous slabs with metal edge trims and U-bars. The failure modes observed were characterized by concrete failure with concrete crushing in the vicinity of bolts and cracks at the slab surface and rib roots. No shear connector fracture was observed due to the high strength of bolts used.

(2) The FE model developed through the ABAQUS can be used to simulate the push off specimen test. The model successfully captured the main structural behaviour including maximum shear resistance and failure modes including concrete crushing and crack position and damage development.

(3) Both experimental and numerical studies demonstrate that the high strength bolts can be used as demountable shear connectors in composite construction. In particular, the use of discontinuous slabs with edge metal trims and Ubars may provide extra confinement and reinforcement to the concrete in the vicinity of the shear connectors. In addition, using discontinuous slabs might make the deconstruction, replacement and repair of composite structures more practical and easier.

\section{Acknowledgement}

The research leading to these results is part of a joint project of the Steel Construction Institute, the University of Luxembourg, the University of Bradford, the Lindab SA, the Tata Steel Ijmuiden BV, the Stichting Bouwen Met Staal, the Technical University of Delft and the AEC3 Ltd. The funding was received from the European Commission: Research Fund for Coal and Steel (RFCS-2015, RPJ, 710040).

\section{References}

[1] Dallam LN, High strength bolt shear connectors - pushout tests, ACI J. 1968; 65 (9): 767-769.

[2] Marshall WT, Nelson HM, Banerjee HK. An experimental study of the use of high strength friction grip bolts as shear connectors in composite beams, Struct. Eng. 1971; 49: 171178.

[3] Dedic DJ, Klaiber WF. High strength bolts as shear connectors In rehabilitation work, Concr. Int. 1984; 6 (7): 41-46.

[4] Hawkins N. Strength in shear and tension of cast in place anchor bolts, Anchorage Concr SP-103, 1987: 233-255.

[5] Ataei A, Bradford MA, Liu X. Experimental study of composite beams having a precast geo polymer concrete slab and deconstructable bolted shear connectors. Engineering Structures 2016; V 114: 1-13.

[6] Lee M, Bradford MA. Sustainable composite beam behaviour with deconstructable bolted shear connectors. Proceeding of the Composite Construction in Steel and Concrete, 2013; VII.

[7] Ataei A, Bradford MA. Finite element analysis of sustainable and deconstructable semi-rigid beam to column composite joints. In 5th ICCM2014. Cambridge, England. 2014; 585590.

[8] Pavlović M, Marković Z, Veljković M, BuĎevac D. Bolted shear connectors vs. headed studs behaviour in push-out tests. Journal of Constructional Steel Research 2013; 88(0): 134149.

[9] Moynihan MC, Allwood J. Viability and performance of demountable composite connectors. Journal of Constructional Steel Research 2014; 99: 47-56. 
[10]Lam D, Saveri E. Shear Capacity of Demountable Shear Connectors. Proceeding of 10th International Conference on Advances in Steel Concrete Composite and Hybrid Structures. Singapore, 2012.

[11]Dai X, Lam D, Saveri E. Effect of Concrete Strength and Stud Collar Size to Shear Capacity of Demountable Shear Connectors. Journal of Structural Engineering 2015; 141(11).
[12]Rehman N, Lam D, Dai X, Ashour A. Experimental study on demountable shear connectors in composite slabs with profiled decking. Journal of Constructional Steel Research 2016; 122: 178-189.

[13]Rehman N, Lam D, Dai X, Ashour A. Testing of composite beam with demountable shear connectors. Proceedings of the Institution of Civil Engineers - Structures and Buildings 2017; 171(1): 3-16. 